\title{
Modeling of alternative testing strategies to demonstrate freedom from Mycobacterium avium ssp. paratuberculosis infection in test-negative dairy herds in the Republic of Ireland
}

\author{
A. Meyer, ${ }^{1 *}$ C. G. McAloon, ${ }^{2}$ J. A. Tratalos,,${ }^{2,3}$ S. J. More,${ }^{2,3}$ L. R. Citer, ${ }^{4}$ D. A. Graham, ${ }^{4}$ and E. S. G. Sergeant ${ }^{1}$ \\ ${ }^{1}$ Ausvet, Bruce, 2617, Australia \\ ${ }^{2}$ UCD School of Veterinary Medicine, University College Dublin, Belfield, Dublin, D04 W6F6, Ireland \\ ${ }^{3}$ UCD Centre for Veterinary Epidemiology and Risk Analysis, University College Dublin, Belfield, Dublin, D04 W6F6, Ireland \\ ${ }^{4}$ Animal Health Ireland, 4 Carrick on Shannon, Co. Leitrim, N41 WN27, Ireland
}

\section{ABSTRACT}

In light of the various adverse effects of Johne's disease on animal productivity and the debate on the role of its causative organism, Mycobacterium avium ssp. paratuberculosis, in the etiology of Crohn's disease, major dairy-producing countries around the world have implemented national control programs aimed at reducing the prevalence of this infection in cattle. A pilot control program was initiated in Ireland in 2013, with a key objective to provide farmers with test-negative dairy herds with tools and knowledge to increase their confidence of freedom over time. The aim of this study was to estimate the confidence of freedom obtained in test-negative Irish dairy herds over time with various sampling scenarios and to evaluate the cost-effectiveness of alternative scenarios for achieving an acceptable level of confidence of freedom in herds with no evidence of infection. A stochastic model was developed to simulate repeated annual testing of individual animals using ELISA and confirmatory assays over a period of 20 yr. Two scenarios modeled the current herd-screening options, whereas 14 alternative scenarios explored the effect of varying parameters from the current testing strategies, such as the frequency of testing, the eligibility criteria for selecting animals, the type of assay, the probability of introduction, and the assay sensitivity. Results showed that the current testing strategy with milk twice a year or serum once a year in all animals over 2 yr old provided the highest annual herd sensitivity, with a median value of $55 \%$. Although the median confidence of freedom increased over time for all scenarios, the time required to reach 90 and $95 \%$ confidence of freedom was highly variable between scenarios. Under the testing scenario where serum tests were used once a year, the confidence of freedom reached $90 \%$ after $4 \mathrm{yr}$

Received April 6, 2018.

Accepted September 7, 2018.

*Corresponding author: anne@ausvet.com.au and $95 \%$ after $7 \mathrm{yr}$ of testing. Some of the alternative scenarios achieved an acceptable level of confidence of freedom in a reasonable timeframe and at lesser cost than the current testing strategies. The results of this work are used to provide recommendations for the next phases of the program.

Key words: Republic of Ireland, Johne's disease, Mycobacterium avium ssp. paratuberculosis, confidence of freedom

\section{INTRODUCTION}

Johne's disease (JD) is a disease of ruminants characterized by chronic granulomatous enteritis, which manifests as a protein-losing enteropathy-causing diarrhea, hypoproteinemia, emaciation, and eventually death (Sweeney, 2011). Adverse effects on animal productivity in terms of lower milk yield (McAloon et al., 2016b), higher cull rates (Hendrick et al., 2005), reduced value for culled animals (Richardson and More, 2009), possible adverse effects on fertility (Johnson-Ifearulundu et al., 2000), and losses due to continued spread of infection are key drivers in the attempt to control JD at the farm level.

In addition, it has been proposed that the causative organism, Mycobacterium avium ssp. paratuberculosis (MAP), could play a role in the etiology of Crohn's disease in humans (Chiodini et al., 1984). Although several potential transmission routes exist (Waddell et al., 2016), currently insufficient evidence exists to clarify the potential public health effects of MAP exposure (Waddell et al., 2015). Food-borne transmission of MAP is of particular importance, and studies have demonstrated MAP resistance to commercial milk pasteurization (Grant et al., 2002). Several major dairy-producing countries around the world have implemented national control programs aimed at reducing JD prevalence in cattle (Geraghty et al., 2014).

Animal Health Ireland was established to provide leadership in the control of nonstatutory diseases in 
Ireland (More et al., 2011). In a Delphi study conducted in 2010, JD was highlighted as one of the priority diseases of the dairy industry to be addressed (More et al., 2010). Based on the lessons from a pilot program run by Animal Health Ireland between 2013 and 2016 and a review of several international programs (Geraghty et al., 2014), the voluntary Irish Johne's Control Programme (IJCP) was launched in 2017.

Herd owners may reduce the potential for the introduction of MAP by implementing bio-exclusion practices, such as the introduction of stock from lowrisk sources. Given imperfect test characteristics and sampling strategies, definite proof of freedom may not be achievable. Instead, a probabilistic approach is used based on the accumulation of evidence (Cameron, 2012). The ability to demonstrate confidence of freedom and the progression of that confidence over time depends upon the sampling strategy and interval employed, the expected true prevalence of infection in the population sampled, and the sensitivity and specificity of the diagnostic tests used (Martin et al., 1992, 2007). Changes in the confidence of freedom are also greatly influenced by the purchasing behavior of the herd in the intervening period (More et al., 2013). To improve decision-making around use of available funding, it is vital to know implications of different testing strategies on herd-level sensitivity and confidence of freedom.

Consistent with the objectives of the program, the early identification of infected herds may highlight farms that could be targeted with knowledge and tools to reduce within-herd MAP transmission. Further, identification of such herds may limit the unknowing sale of infected animals. Several MAP-screening tests are available, including whole-herd testing, bulk tank testing, cull cow testing, and environmental testing. In the current work, we only considered testing strategies based on serum and milk testing. The costs associated with each testing strategy will depend on the sampling and testing strategies, including follow-up and confirmatory testing as well as test characteristics and costs. Therefore, one aim of our study was to estimate the effect of varying the sampling frequency, interval, and sample size on confidence of freedom in test-negative Irish dairy herds over time. A second aim was to evaluate the cost-effectiveness of alternative scenarios for achieving an acceptable level of confidence of freedom in herds with no evidence of infection.

\section{MATERIALS AND METHODS}

\section{General Approach}

A stochastic simulation model was developed using R software, version 3.3.3 (R Core Team, 2017). Some of the graphical outputs were produced using the $\mathrm{R}$ packages ggplot2 (Wickham, 2009) and gridExtra (Auguie, 2016). The model simulated repeated testing of a dairy cattle herd for the presence of MAP infection and estimated the resulting herd-level sensitivity and the updated confidence of freedom for each year of the simulation. The confidence of freedom from infection was updated each year using a framework previously described (Martin et al., 2007). The model ran over $20 \mathrm{yr}$ with a time step of $1 \mathrm{yr}$ to accommodate the chronic nature of MAP infection. Key model inputs were entered as probability distributions to reflect uncertainty about their true values. A range of scenarios were modeled to estimate the effect of varying the sampling frequency, interval, and sample size used in the current program on the outputs. Each scenario was simulated for 50,000 iterations and key outputs were summarized as medians and $95 \%$ prediction intervals. Under the conditions of the IJCP, herd owners may elect to use either a milk ELISA or a serum ELISA for herd screening. Herd owners opting to use milk ELISA must test all eligible animals twice per year, with an interval of at least $90 \mathrm{~d}$ between samplings. Nonlactating eligible animals, such as males and dry cows, must be tested by serum ELISA. Herd owners electing to use serum ELISA for all eligible animals are only required to sample animals once per year. These herd-screening options were modeled as scenarios 1 and 4, respectively. Fourteen additional scenarios, which were considered feasible and realistic and had been agreed upon by the stakeholders involved, were also modeled. These additional scenarios were defined by varying parameters from the current scenarios, such as the frequency of testing, the eligibility criteria for selecting animals, the type of assay, the probability of introduction, and the assay sensitivity. All scenarios are described in Table 1. Scenarios 5 to 10 were divided in 2 periods, where period 1 is similar to current practices, whereas the testing intensity is reduced during period 2 .

\section{Model Input Data}

Herd Size. Animal population and movement data were extracted for the period July 1, 2015, to June 30, 2016, from the Animal Identification and Movement database maintained by Ireland's Department of Agriculture, Food and the Marine. The study was limited to those herds classified as dairy by the Irish Cattle Breeding Federation and which had at least 1 calf born between the above dates. Herds with $<20$ females aged 2 yr or older or with several movements in or out of the herd $>70 \%$ of the number of females aged 2 yr or older were excluded as not representative of Irish commercial dairy herds. The population and movement data of the 
Table 1. Definitions and features for each of the 16 testing scenarios used in the model

\begin{tabular}{|c|c|c|}
\hline $\begin{array}{l}\text { Scenario } \\
\text { number }\end{array}$ & Scenario name & Scenario features \\
\hline 1 & $\begin{array}{l}\text { Milk twice or serum once a year } \\
\text { (current) }\end{array}$ & $\begin{array}{l}\text { All animals } \geq 2 \text { yr old tested with either milk ELISA twice per year (cows in milk) or } \\
\text { serum ELISA once per year (males and dry cows). }\end{array}$ \\
\hline 3 & Milk or serum test once a year & $\begin{array}{l}\text { All animals } \geq 2 \text { yr old tested once per year (females in milk with milk ELISA, males and } \\
\text { dry females with serum ELISA). }\end{array}$ \\
\hline 4 & Serum test once a year (current) & All animals $\geq 2$ yr old tested every year with a single serum ELISA \\
\hline 6 & Older animals, serum only & $\begin{array}{l}\text { Period } 1 \text { ( } 2 \text { yr): scenario } 4 \text {; period } 2 \text { (rest of the simulation): all animals } \geq 3 \text { yr old tested } \\
\text { once a year (serum ELISA). }\end{array}$ \\
\hline 7 & Reduced frequency, milk or serum & $\begin{array}{l}\text { Period } 1 \text { ( } 2 \text { yr): scenario } 3 \text {; period } 2 \text { (rest of the simulation): all animals } \geq 2 \text { yr old tested } \\
\text { every second year (females in milk with milk ELISA, males and dry females with serum } \\
\text { ELISA). }\end{array}$ \\
\hline 8 & Reduced frequency, serum only & $\begin{array}{l}\text { Period } 1 \text { ( } 2 \text { yr): scenario } 4 \text {; period } 2 \text { (rest of the simulation): all animals } \geq 2 \text { yr old tested } \\
\text { every second year (serum ELISA). }\end{array}$ \\
\hline 11 & Increased risk of introduction & Scenario 3 with increased probability of introduction \\
\hline 12 & Decreased risk of introduction & Scenario 3 with null probability of introduction \\
\hline 13 & Decreased assay sensitivity (10\%) & Scenario 3 with sensitivity of the confirmatory assay reduced by $10 \%$ \\
\hline 14 & Decreased assay sensitivity (20\%) & Scenario 3 with sensitivity of the confirmatory assay reduced by $20 \%$ \\
\hline 15 & Closed herd, 1 yr of testing only & $\begin{array}{l}\text { Period } 1 \text { ( } 1 \text { yr): scenario } 3 \text { with null probability of introduction; period } 2 \text { (rest of the } \\
\text { simulation): no testing with null probability of introduction. }\end{array}$ \\
\hline 16 & Closed herd, 4 yr of testing only & $\begin{array}{l}\text { Period } 1 \text { ( } 4 \text { yr): scenario } 3 \text { with null probability of introduction; period } 2 \text { (rest of the } \\
\text { simulation): no testing with null probability of introduction. }\end{array}$ \\
\hline
\end{tabular}

remaining herds were used as probability distributions for the following model inputs: number of animals in each sex-age group, number of animals introduced annually, and number of animals having left the herd annually. The population of interest was assumed to be constituted of animals aged $2 \mathrm{yr}$ and older. Therefore, the term herd size refers to the number of animals aged $2 \mathrm{yr}$ and older in the remainder of this document.

Test Sensitivity and Specificity. It was assumed that any ELISA-positive result would be followed by a fecal culture (FC) or PCR assay (the use of either of these tests is hereafter referred to as a confirmatory assay) to confirm infection and provide assumed $100 \%$ specificity. The 2 tests would be interpreted in series, and therefore the sensitivities of the combined tests [a milk ELISA followed by a confirmatory assay $\left(S e_{\text {milk }}\right)$ and a serum ELISA followed by a confirmatory assay $\left.\left(S e_{\text {serum }}\right)\right]$ were calculated as the product of the sensitivity of the milk or serum ELISA and the sensitivity of the confirmatory assay in ELISA-positive animals.

Estimates of serum ELISA sensitivity and specificity were obtained for the target condition "infected," which was in line with the definitions proposed by Nielsen and Toft (2008). Infected animals were those that carry MAP intracellularly but may not necessarily be shedding (infectious) or exhibiting clinical signs (affected). It is important to note that the condition infected here also includes infectious and affected animals. An existing literature review of the performance of antemortem tests (Nielsen and Toft, 2008) was supplemented with an additional search for target condition infected in all published literature from 2007. The commercial ELISA kits most commonly used in Ireland to detect MAP infection in dairy herds are the Paratuberculosis Antibody Screening Test (Idexx, Westbrook, ME) and the ID Screen (IDVet, Montpellier, France) kits. As they are very similar, we did not distinguish between these kits when calculating the test sensitivity and specificity. Beta distributions were constructed for each test from central and dispersion estimates found in the literature (Vose, 2000). The sensitivity of the serum ELISA test was modeled by a beta distribution with a mode of 0.15 and upper 95th percentile of 0.30 , whereas the sensitivity of the milk ELISA test was modeled by a beta distribution with a mode of 0.13 and upper 95 th percentile of 0.26 (van Weering et al., 2007; Nielsen and Toft, 2008; Pozzato et al., 2011; More et al., 2013; McAloon et al., 2016a). Summary estimates of the specificity for these ELISA kits ranged from 0.98 to 1.00 (Nielsen and Toft, 2008; Nielsen et al., 2013). Consequently, the specificity of the ELISA test was modeled by a beta distribution with a mode of 0.990 and upper 95th percentile of 0.995 (McAloon et al., 2016a). The sensitivity of the fecal culture in ELISA-positive animals was modeled by a 
Pert distribution with a minimum of 0.60 , mode of 0.65, and maximum of 0.70 (Nielsen et al., 2002b; More et al., 2013).

Estimates for performance of PCR vary widely. Possible reasons include differences in the samples used (e.g., naturally infected or spiked individual fecal samples or environmental samples), variations in the extraction and purification methods used, differences in the PCR kits used themselves, and likely laboratory variation. Of publications reporting the sensitivity of PCR relative to fecal culture, the sensitivity reported is often in the range of 0.50 to 0.70 (Plain et al., 2014; Acharya et al., 2017). However, in the majority of studies, several subclinical samples are often positive on PCR but negative on fecal culture (Logar et al., 2012). This was also the case when a longitudinal case definition was used in cows repeatedly sampled over 12 mo. Kralik et al. (2014) showed that, within infected herds, a large proportion of these additional positive samples are likely due to pass through in the presence of highshedding animals, representing a decrease in individual specificity; in the rest of the studies reported, it was not possible to know whether this was also the case. Further, the potential reduction in specificity within infected herds was not of particular importance for our study, as it is the herd-level diagnosis that is ultimately of key interest. Therefore, for the purpose of our study, a PCR sensitivity and specificity of 1.0 relative to fecal culture was used (scenarios 1 to 12), with additional values of 0.8 and 0.9 to assess the effect of varying this estimate (scenarios 13 and 14).

Further, the ELISA test sensitivity is known to be particularly poor in younger animals, such as those in their first lactation (Nielsen et al., 2002a). Therefore, a multiplying factor was applied to the ELISA test sensitivities presented above when used in animals aged 3 yr and older (scenarios 4, 6, 8, and 9). We calculated the average sensitivity in animals $2 \mathrm{yr}$ and older and 3 yr and older, respectively, using published age-specific sensitivity estimates (Nielsen et al., 2013; Meyer et al., 2018) and Irish dairy herd population data. The 2 values obtained (1.09 and 1.17) were used as parameters for a uniform distribution to model $F_{\geq 3}$, the multiplying factor applied to the ELISA test sensitivity in animals aged $2 \mathrm{yr}$ and older (presented above), to obtain the ELISA test sensitivity in animals aged 3 yr or older.

Within-Herd Prevalence in Source Herds. Whole-herd MAP screening data and within-herd true prevalence estimates were obtained from the pilot phase of the program. All test results for enrolled dairy herds are stored centrally in the Irish Cattle Breeding Federation database. Available individual animal test data were extracted from November 1, 2013, to Decem- ber 31,2017 . Individual data were aggregated to the herd level to include number of animals tested, number positive, and sample matrix used (hereafter herd tests). Next, the within-herd true prevalence for each herd was estimated using Rogan-Gladen estimation (Rogan and Gladen, 1978), including the sensitivity and specificity of the test kits used. The mode of the distributions described above was used as a point estimate of the sensitivity for the Idexx and IDVet kits (0.15 for serum tests and 0.13 for milk tests). In addition to the Idexx and IDVet kits, the Paracheck 2 Kit (Thermo Fisher Scientific, Waltham, MA) was also used in the pilot phase. The literature search described above provided 2 relevant studies from which a sample size weighted mean of 0.22 was calculated for the sensitivity of the Paracheck 2 kit (Jubb et al., 2004; Alinovi et al., 2009). The mode of the distribution described above (0.99) was used as a point estimate of the specificity for the 3 ELISA kits, which was consistent with the estimate used in other studies (McAloon et al., 2016a).

Herds with less than 20 animals tested or with an estimated true prevalence of infection over 0.90 were excluded as not representative of Irish commercial dairy herds. The maximum number of animals tested at a single point in time during the study period was extracted for each herd, and herd tests performed on less than $80 \%$ of that maximum number were dropped for each herd to avoid retaining follow-up tests performed on a subset of positive animals. Finally, the most recent herd test was retained for each of the remaining herds.

For scenarios other than 11, 12, 15, and 16, we extracted the estimated total number of infected animals $i$ and the total number of animals tested $t$ from those of the remaining herds having a true prevalence equal to or under $5 \%$ to model the biosecurity practices consistent with implementation of one aspect of the veterinary risk assessment and management plan (VRAMP): the sourcing of replacement animals only from low-risk herds. Assuming the introduced animals were sourced independently from this population, the probability of an introduced animal being MAP-infected $\left(P_{\text {source }}\right)$ was estimated from a beta distribution with parameters $i+$ 1 and $t-i+1$. For scenario $11, i$ and $t$ were calculated using all the herds to model insufficient biosecurity practices and the lack of, or an ineffective, VRAMP. For scenarios 12, 15, and 16, we assumed that increased biosecurity measures would decrease the probability of introduction to 0 (closed herd).

\section{Model Outputs}

Herd-Level Sensitivity. The herd-level sensitivity in year $y\left(\mathrm{SeH}_{y}\right)$ was defined as the probability of at 
Table 2. Calculation of the herd-level sensitivity in each scenario

\begin{tabular}{|c|c|}
\hline Scenarios and periods & Herd-level sensitivity $^{1}$ \\
\hline \multirow[t]{2}{*}{ Scenario 1} & $\begin{array}{l}S e H_{y}=1-\left(1-S e_{\text {avg }}\right)^{d} \\
\text { with } S e_{\text {avg }}=\frac{n_{\text {milk }} \times S e_{\text {milk }} \text { ombined }}{N}+n_{\text {serum }} \times S e_{\text {serum }} \\
N\end{array}$ \\
\hline & $S e_{\text {milk }}{ }_{\text {combined }}=1-\left(1-S e_{\text {milk }}\right)^{2}$ \\
\hline Scenarios $2,3,4,11,12,13$, and 14 & $S e H_{y}=1-\left(1-S e_{a v g}\right)^{d}$ \\
\hline Period 2 of scenarios 5 and 6 & $\mathrm{SeH}_{y}=1-\left(-F_{\geq 3} \times S e_{\text {milk }} \times \frac{n_{\text {milk }}}{N}\right)^{d} \times\left(1-F_{\geq 3} \times S e_{\text {serum }} \times \frac{n_{\text {serum }}}{N}\right)$ \\
\hline $\begin{array}{l}\text { Odd years of Period } 2 \text { of scenarios } 7,8 \text {, and } 10 \\
\text { Period } 2 \text { of scenarios } 15 \text { and } 16\end{array}$ & $\mathrm{SeH}_{y}=0$ \\
\hline
\end{tabular}

${ }^{1} d=$ assumed number of infected animals in the herd; $F_{>3}=$ multiplying factor applied to the ELISA sensitivity in animals aged 2 yr and older; $N=$ herd size; $n_{\text {entries }>2}=$ number of animals over $2 \mathrm{yr}$ introduced that year; $n_{\text {exits }>2}=$ number of animals over $2 \mathrm{yr}$ having left the herd that year; $n_{\text {milk }}\left(n_{\text {serum }}\right)=$ number of herd animals tested with a milk (serum) ELISA that year; $P_{\text {source }}=$ probability of an animal introduced being MAP-infected; $\mathrm{SeH}_{y}=$ herd-level sensitivity in year $y$.

least 1 animal testing positive during year $y$ given that the herd is infected at a prevalence equal to or greater than the design prevalence. The herd-level sensitivity was calculated each year using approximations of the hypergeometric and binomial probability distributions (Cameron and Baldock, 1998), as presented in Table 2 . The design prevalence was set as $5 \%$ by agreement among the relevant stakeholders. In scenarios where only a sample of the herd was tested, the assumed number of infected animals $(d)$ was calculated as the product of the design prevalence and the herd size rounded up to the next integer. Sensitivity analysis was conducted by using alternative values of 1 and $3 \%$ for the design prevalence in scenarios 1,3 , and 5 (results shown in Appendix).

Confidence of Freedom. The confidence of freedom in year $y\left(\right.$ PFree $\left._{y}\right)$, that is, the probability that the true herd prevalence is less than the specified design prevalence given negative test results, was estimated as follows (Martin et al., 2007):

$$
\text { PFree }_{y}=\frac{\text { Prior }_{y}}{1-\text { SeH }_{y} \times\left(1-\text { Prior }_{y}\right)},
$$

where Prior $_{y}$ was the prior probability of freedom for year y. Prior $_{y}$ was calculated from the confidence of freedom for year $y-1$, discounted for the probability of introduction of infection in year $y-1, P_{\text {introduction }}$ :

$$
\text { Prior }_{y}=1-\left[\begin{array}{l}
1-\text { PFree }_{y-1}+P_{\text {introduction }}- \\
\text { introduction } \times\left(1-\text { PFree }_{y-1}\right)
\end{array}\right],
$$

where $P_{\text {introduction }}$ is the probability that infection is introduced or exceeds the design prevalence during the time period, either from newly introduced infection or by increase in prevalence of existing infection from a level below the design prevalence (Martin et al., 2007). Because the aim of our analysis was to simulate herds that are expected to be free of infection, progression of existing infection was not specifically considered in this analysis, and $P_{\text {introduction }}$ was estimated from the numbers of animals introduced into the simulated herd, using a binomial probability distribution:

$$
P_{\text {introduction }}=1-\left(1-P_{\text {source }}\right)^{n_{\text {entries }}} \text {, }
$$

where $n_{\text {entries }}$ was the total number of animals introduced in the herd during that year. For the first year of the simulation, the prior probability of freedom was estimated as 1 minus the average herd-level JD prevalence in Irish dairy herds enrolled in the national control program (McAloon et al., 2016a).

Testing Costs. For each scenario and year of simulation, the annual cost of the testing program was calculated by adding the costs for all the individual ELISA and confirmatory assays performed that year. 
The number of confirmatory assays (FC or PCR) was estimated using a binomial probability distribution with parameters the number of ELISA tests performed that year and the complement of the ELISA specificity. As this work was targeted toward JD-free herds, all animals were expected to be free of infection and all positive ELISA results were expected to be arising from false-positive animals. Current costs were obtained from the IJCP, namely $€ 5.86$ per serum ELISA test, $€ 2.75$ per milk ELISA test, and €40.00 per confirmatory assay, including collection costs. The total testing costs over 5-yr and 20-yr periods as well as the testing costs to reach $90 \%$ and $95 \%$ confidence of freedom were also extracted.

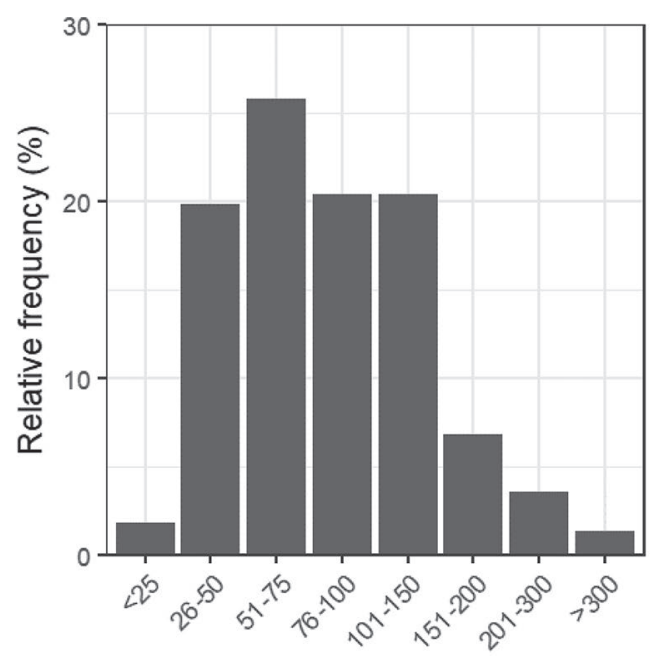

Herd size - aged 2 years and older

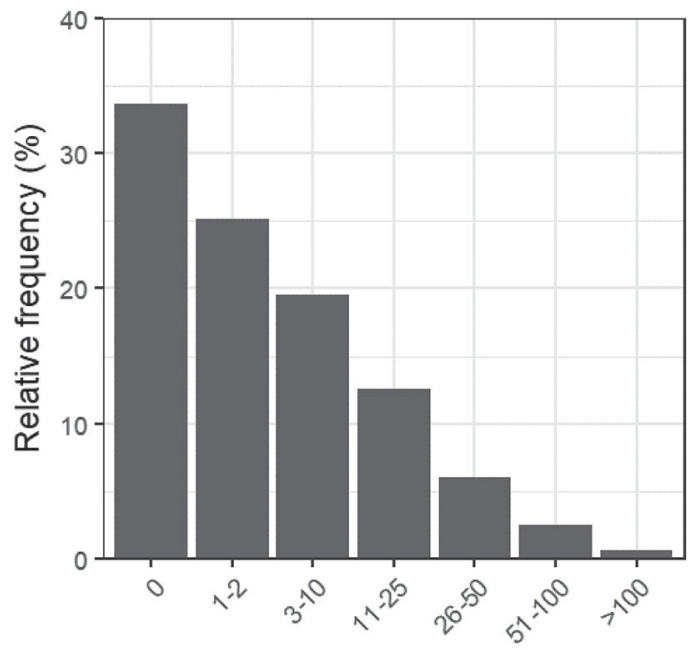

No. introductions - all ages

\section{RESULTS}

\section{Model Inputs}

Valid herd sizes and movement data were obtained from 14,130 herds (Figure 1, upper left panel). The distribution of the number of introductions for the year July 2015 to June 2016 presented a long upper-tail (Figure 1, lower left panel), as 34\% of the herds did not introduce any animals, whereas $64 \%$ of the herds did not introduce any animals over $2 \mathrm{yr}$ old. The proportion of introductions during this period relative to the herd size was $<5 \%$ for $45 \%$ of the herds having introduced at least 1 animal (Figure 1, lower right panel). Valid herd
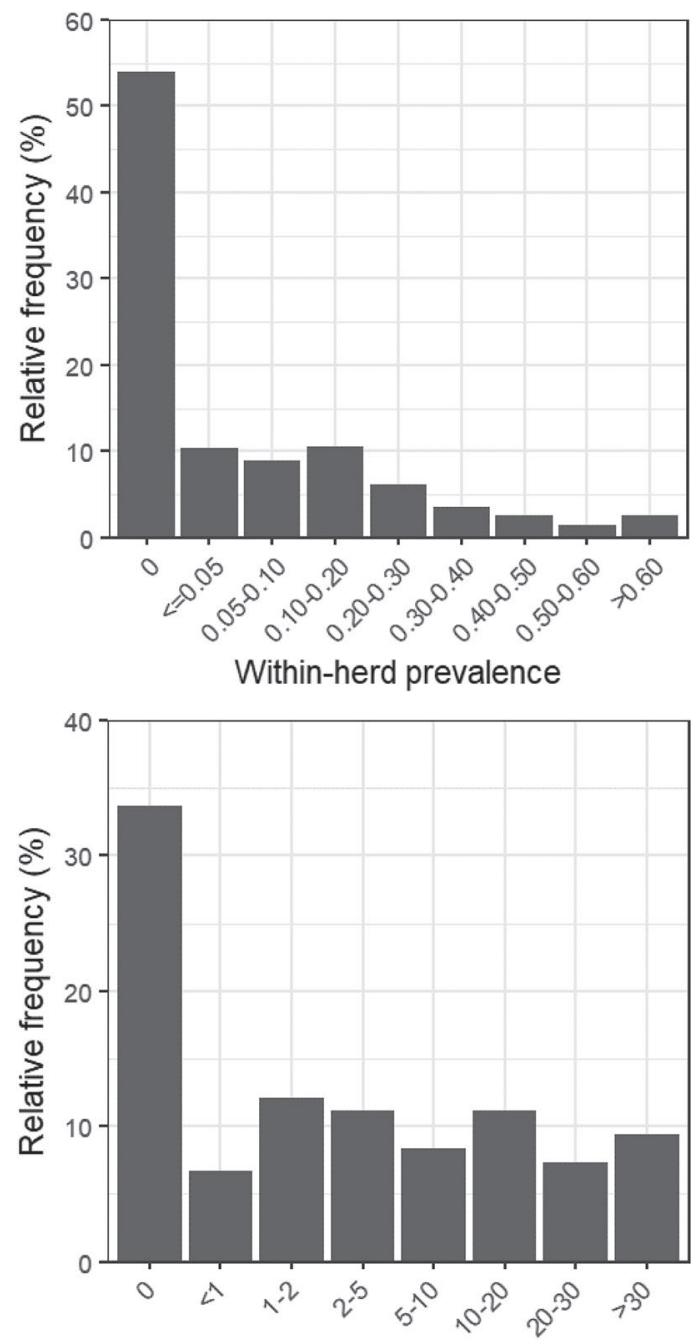

Introductions as $\%$ of herd size

Figure 1. Bar plots showing the distribution of key input parameters (July 2015 to June 2016): herd size (upper left panel), within-herd prevalence (upper right panel), number of introductions during this period (lower left panel), and introductions as a percentage of the herd size (lower right panel). 


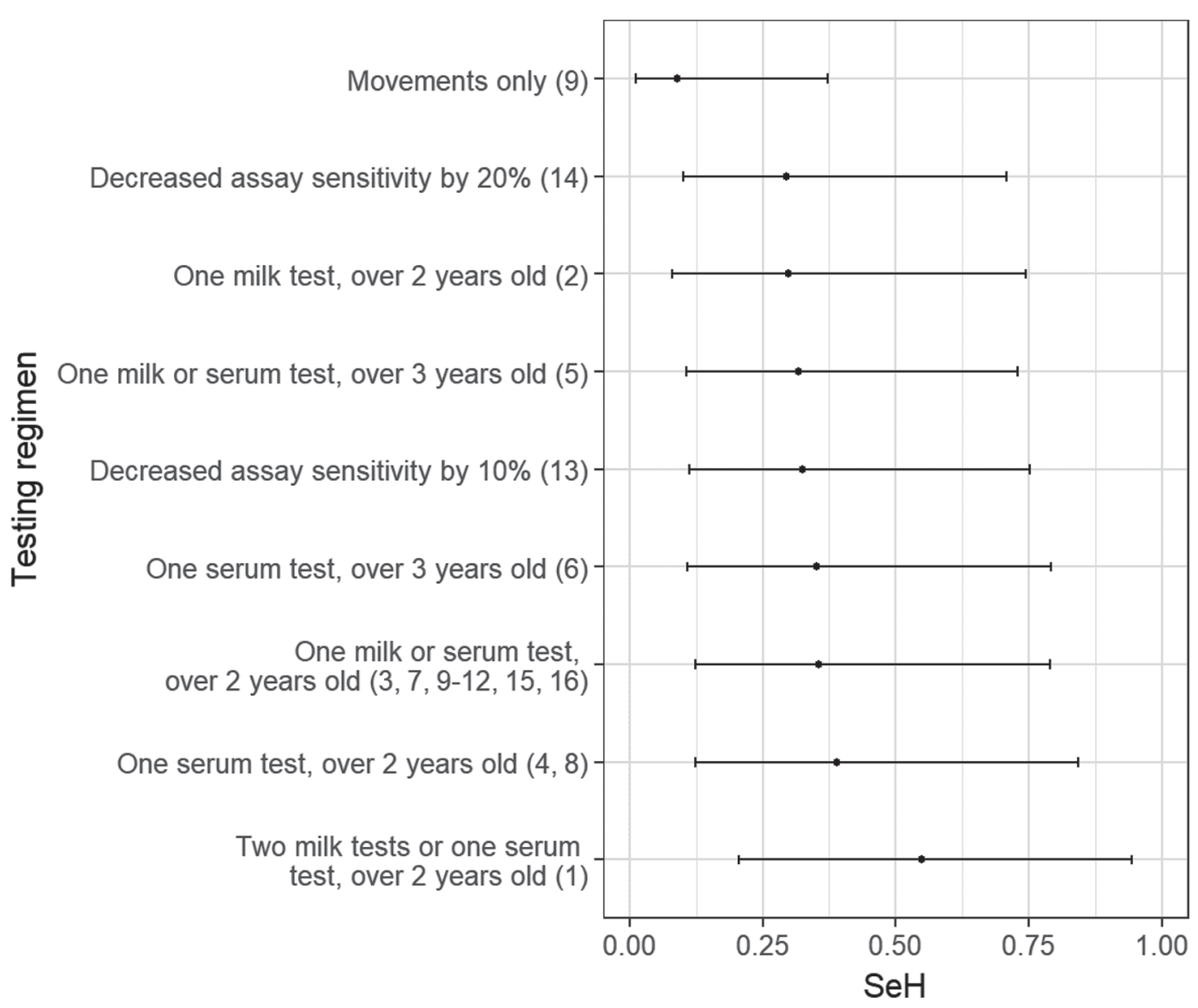

Figure 2. Plot of the annual herd-level sensitivity $(\mathrm{SeH})$ obtained with each testing strategy. The plots show the median estimate (dot) and the $95 \%$ prediction interval (bar). The numbers in brackets indicate the scenario(s) in which each testing strategy is used

prevalence data were available for 1,523 herds (Figure 1, upper right panel).

\section{Herd-Level Sensitivity}

The current testing strategy (scenario 1; milk twice a year for eligible lactating cows, serum once a year in all other eligible animals, eligible animals being over $2 \mathrm{yr}$ of age) provided the highest annual herd sensitivity, with a median of $55 \%$ (Figure 2). All other testing strategies had lower herd sensitivity values, with median estimates ranging from 9 to $39 \%$. The sensitivity estimates calculated in the model had very broad prediction intervals, covering between 62 and $72 \%$ of the possible interval (0 to 1 ). According to the sensitivity analysis, herd size was the most influential parameter in the calculation of the herd-level sensitivity in scenario 3, whereas number of introductions was most influential on confidence of freedom (Figure 3). Under the conditions of this particular scenario, the diagnostic sensitivity of the milk ELISA was more influential than that of the serum ELISA, because fewer tests were conducted on serum (median $\mathrm{n}=3$ per year) than milk (median $\mathrm{n}=66$ per year). The median number of confirmatory assays over the entire simulation period was $\leq 20$ in all scenarios and represented between 8 and $19 \%$ of the total costs depending on the scenario.

\section{Confidence of Freedom}

The median confidence of freedom increased over time for all scenarios (Figure 4). The width of the prediction intervals of the confidence of freedom also increased over time, with the exception of scenario 12 (Figure 4). Overall, the time required to reach 90 and $95 \%$ confidence of freedom was highly variable between scenarios (Figure 5 and Table 3). Under the current testing requirements, the confidence of freedom reached $90 \%$ after 2 (scenario 1, milk twice or serum once a year) and $4 \mathrm{yr}$ of testing (scenario 4 , serum test once a year); it reached $95 \%$ after 4 and 7 yr of testing, respectively. After 5 yr of testing, the final confidence of freedom was 97.5 and $93.4 \%$ in scenarios 1 and 4 , respectively. None of the alternative scenarios achieved 
90 or $95 \%$ confidence of freedom as fast as scenario 1 ; however, some scenarios achieved comparable performances with scenario 4 . Scenarios 3, 5, 6, 12, and 13 reached a confidence of freedom of $90 \%$ or higher after 5 yr, as obtained with the current strategies.

\section{Scenario Analysis}

Scenario 3. Reducing the testing frequency to once a year in herds using milk tests (scenario 3) increased the time to reach 90 and $95 \%$ confidence of freedom to values similar to scenario 4 ( 4 and $8 \mathrm{yr}$, respectively). The final confidence of freedom was also similar to that of scenario 4 . The cumulative testing costs over $5 \mathrm{yr}$ for scenario 3 were $43 \%$ lower than those of scenarios 1 and 4 .
Scenario 2. Reducing the testing intensity even further, by testing only females in milk once a year (scenario 2), increased the time to reach 90 and $95 \%$ confidence of freedom to 6 and $11 \mathrm{yr}$, respectively. The confidence of freedom after 5 yr was $89.2 \%$. The overall testing costs were decreased by $58 \%$ compared with those of scenario 1.

Scenario 5. When only older animals were tested using both milk and serum tests, the time to reach 90 and $95 \%$ confidence of freedom noticeably increased when compared with the current strategy where all animals are tested twice a year (scenario 1). However, this protocol only increased the time to reach 90 and $95 \%$ confidence of freedom by 1 yr when compared with scenario 3 (milk or serum test once a year). The confidence of freedom after $5 \mathrm{yr}$ was $91.1 \%$. The testing
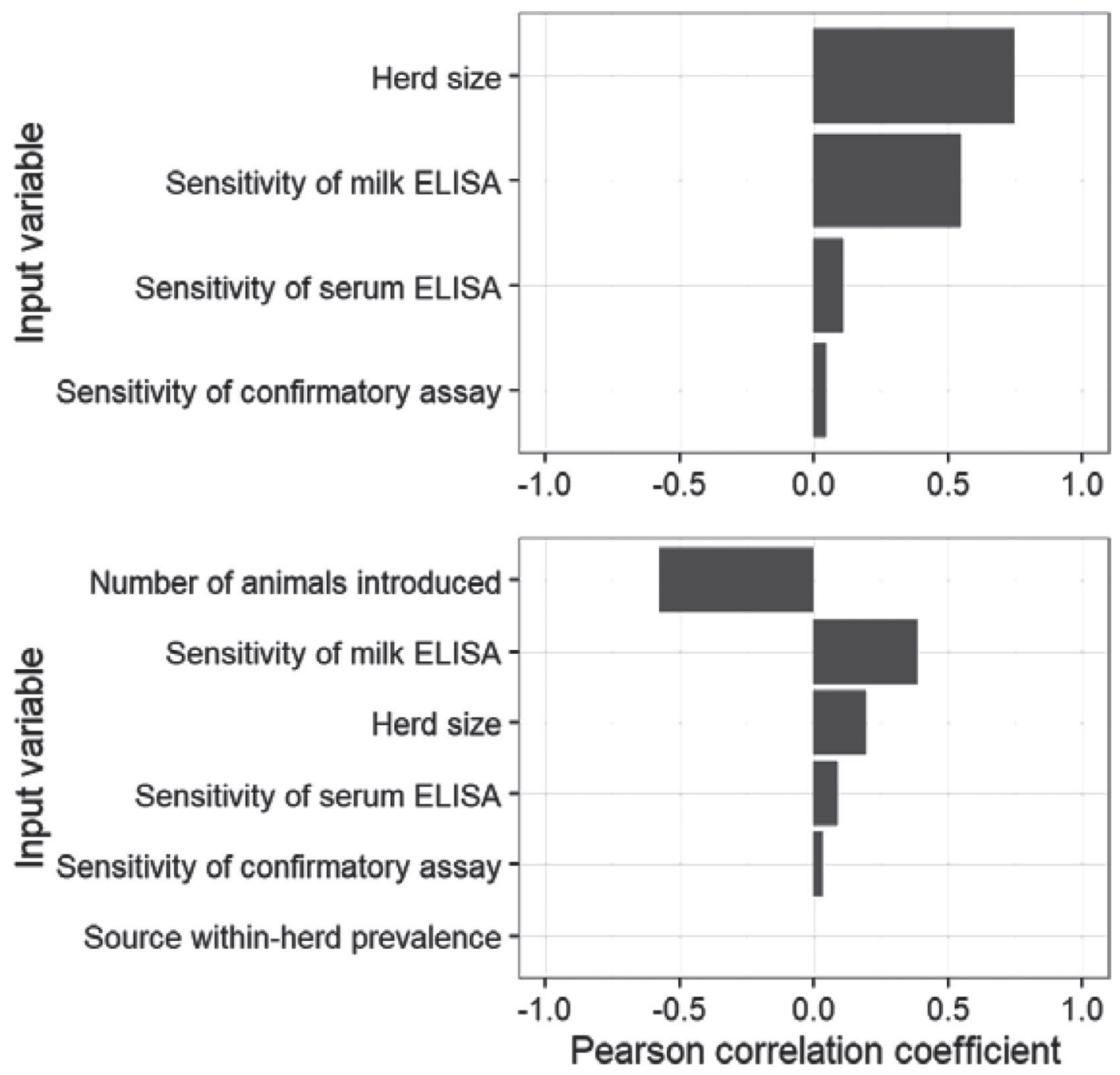

Figure 3. Tornado plots of the correlation between the annual herd-level sensitivity (upper panel) and confidence of freedom after 5 yr (lower panel) as well as relevant input variables for scenario 3 

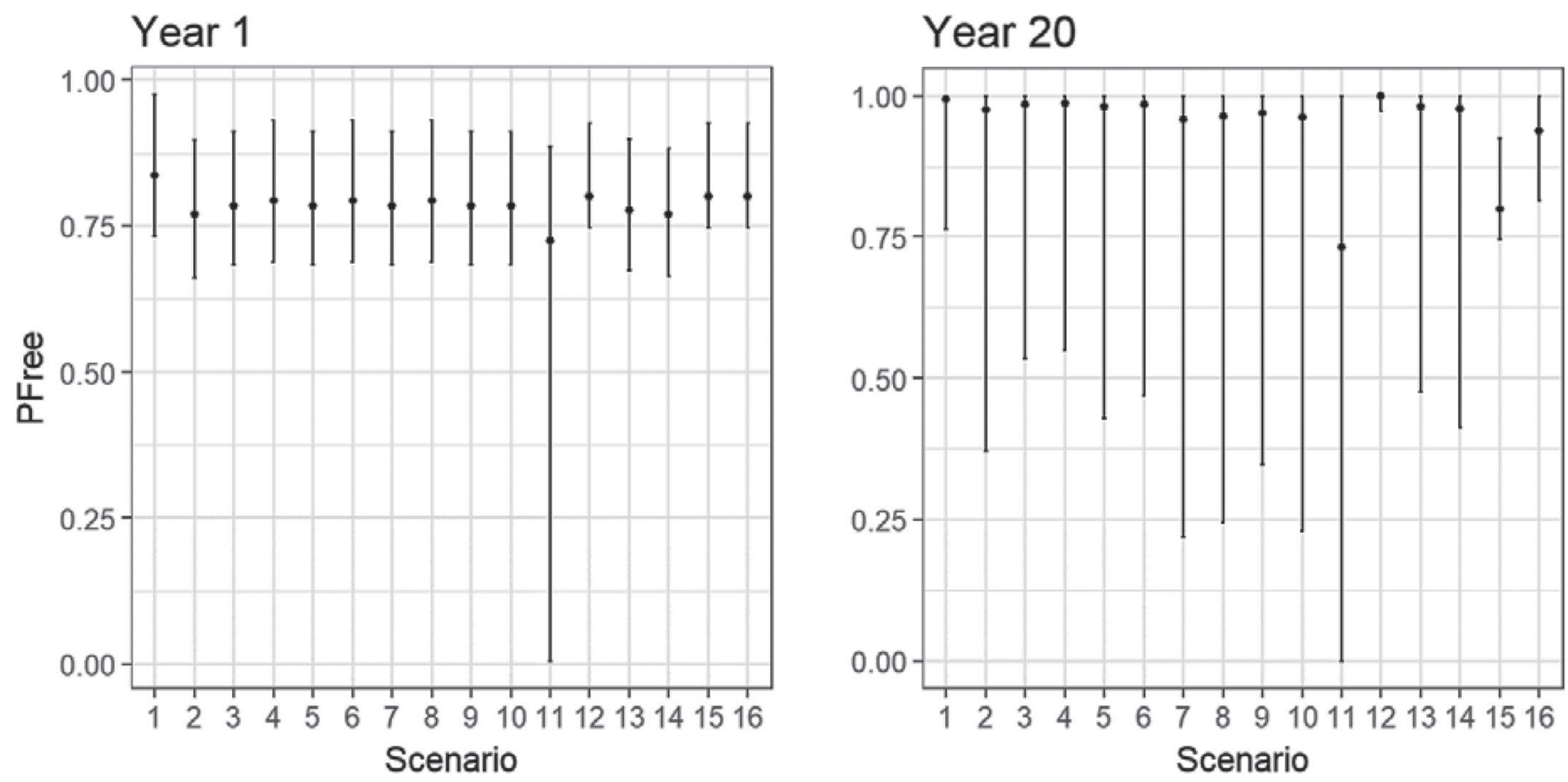

Figure 4. Plots of the confidence of freedom (Pfree) by scenario for the first (left panel) and last (right panel) year of the simulation. The plots show the median estimate (dot) and the $95 \%$ prediction interval (bar)

costs over 5 yr of this scenario were 52 and $15 \%$ lower than those of scenarios 1 and 3, respectively.

Scenario 6. When only older animals were tested using serum tests, the time to reach $90 \%$ confidence of freedom was not affected when compared with the current strategy where all animals are tested serologically once a year (scenario 4 ), and the time to reach a $95 \%$ confidence of freedom only increased by $1 \mathrm{yr}$. This scenario decreased the confidence of freedom after $5 \mathrm{yr}$ from 93.4 to $92.5 \%$ only and reduced the testing costs over 5 yr by $13 \%$.

Scenarios 7 and 8. Reducing the testing frequency to every second year substantially increased the time to reach 90 and $95 \%$ confidence of freedom when compared with the relevant current strategy. This scenario also decreased the confidence of freedom after $5 \mathrm{yr}$ to 85.2 and $86.3 \%$ for scenarios 7 (milk and serum tests) and 8 (serum tests only), respectively. The effect on the testing costs over 5 yr was large, as they were 66 and $40 \%$ lower than those of scenarios 1 and 4, respectively.

Scenario 9. Adding movement testing in years when whole-herd testing was not performed (scenario 9) reduced the time to reach 90 and $95 \%$ level in confidence of freedom by 2 and $4 \mathrm{yr}$, respectively, compared with scenario 7 , where this was not practiced. It allowed the confidence of freedom to reach $87.3 \%$ after 5 yr of simulation but increased the testing costs by $25 \%$.
Scenario 10. Reducing the testing frequency after $4 \mathrm{yr}$ instead of 2 (scenario 10) decreased the time to reach 90 and $95 \%$ confidence of freedom by 4 and $2 \mathrm{yr}$, respectively, compared with scenario 7 . Further, it only increased the overall testing costs by $9 \%$.

Scenarios 11, 12, 15, and 16. In the scenario modeling an increased probability of disease introduction (scenario 11), the median confidence of freedom reached a maximum of $73.0 \%$ only. By comparison, decreasing the probability of introduction to zero (scenario 12) decreased the time to reach 90 and $95 \%$ confidence of freedom by 1 and $3 \mathrm{yr}$, respectively, compared with the equivalent scenario with the original probability of introduction (scenario 3). In scenario 12, the confidence of freedom reached $95.9 \%$ after 5 yr and almost $100 \%$ after 20 yr. When testing was ceased after 1 and 4 yr in closed herds (scenarios 15 and 16, respectively), the final confidence of freedom did not reach the $95 \%$ level. One year of testing provided an $80 \%$ confidence of freedom (scenario 15), whereas 4 yr provided a $93.7 \%$ confidence of freedom, after which confidence of freedom plateaued. The testing costs were decreased by 95 and $80 \%$ in scenarios 15 and 16 , respectively, when compared with continuous testing for $20 \mathrm{yr}$.

Scenarios 13 and 14. Considering a lower sensitivity of the confirmatory assay (to model the use of a confirmatory test that may be less sensitive than originally 
assumed) increased the time to reach $90 \%$ confidence of freedom by 1 and 2 yr for scenarios 13 (sensitivity of $90 \%$ of original value) and 14 (sensitivity of $80 \%$ of the original value) when compared with scenario 3 . It increased the time to reach a $95 \%$ confidence of freedom by 1 and 3 yr for scenarios 13 and 14, respectively, compared with scenario 3 .
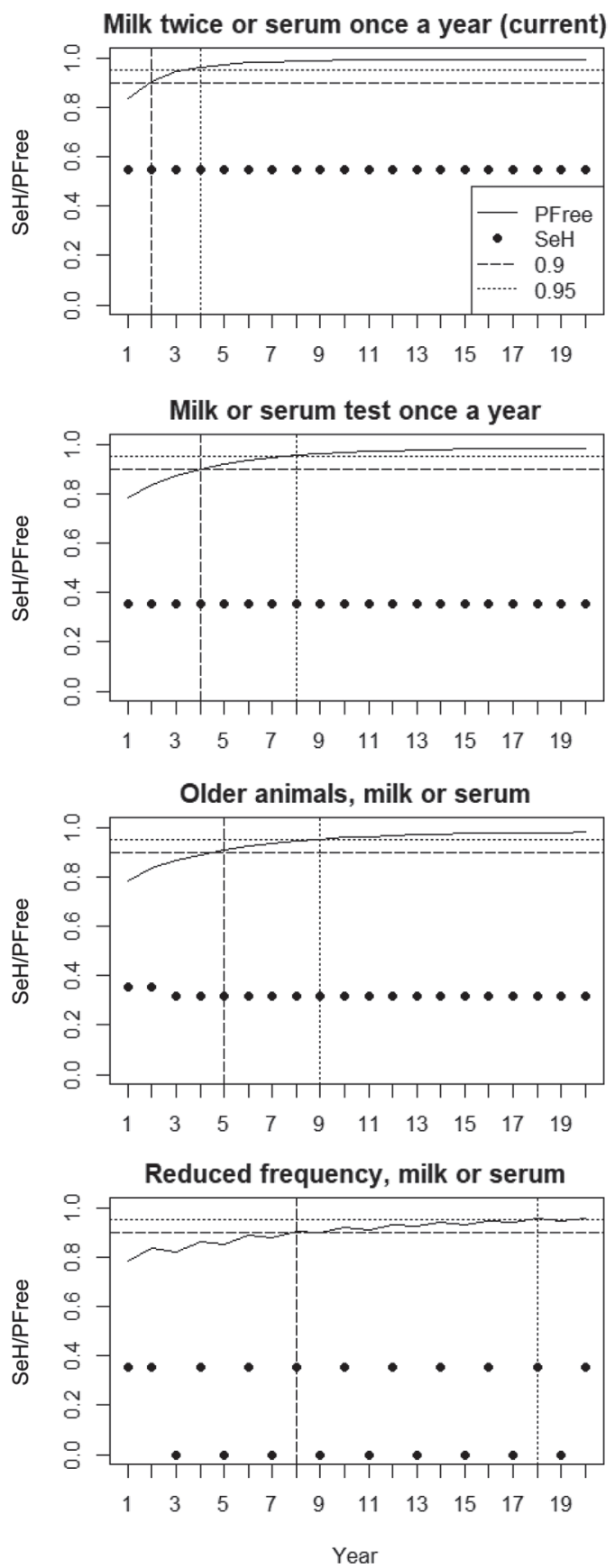

\section{DISCUSSION}

This work presents estimates for herd sensitivity and confidence of freedom as median values and $95 \%$ prediction intervals, incorporating uncertainty in model inputs and variability in herd size across the Irish dairy industry. In general, larger herds tend to
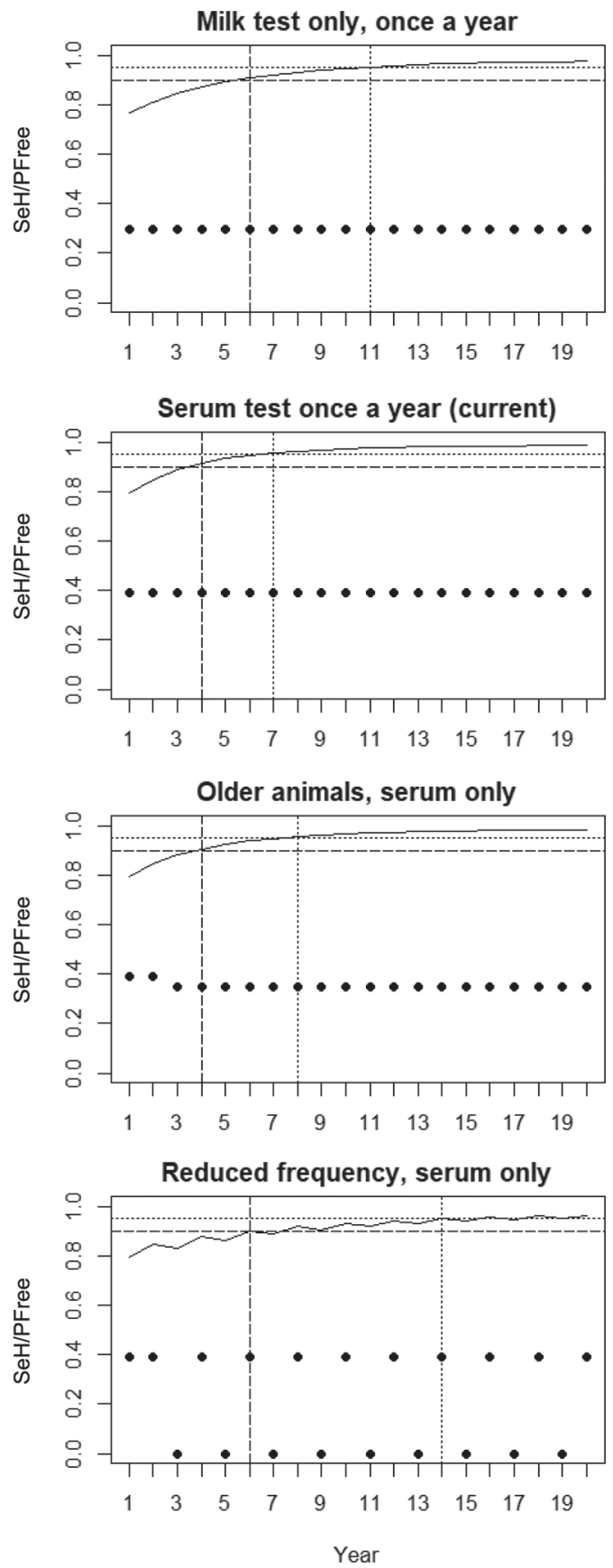

Figure 5. Plots of the median confidence of freedom (Pfree, blue lines) and annual herd sensitivity (SeH, black dots) by year and scenario. The time until the median Pfree reaches 90\% (respectively, 95\%) is represented using a dashed red (respectively, black) line. 
have higher herd sensitivity estimates, both because of the larger numbers of infected animals present and the use of a modeling strategy based on whole-herd testing; therefore, these herds progress faster toward the target confidence of freedom, whereas smaller herds will have lower herd sensitivity and make slower progress. Similarly, herds with nil or few introductions of only low-risk animals will have nil to low probability of introduction and will make faster progress when compared with herds with larger numbers of high-risk introductions. Overall, the broad prediction intervals associated with the herd sensitivity estimates are likely due to a combination of uncertainty about the diagnostic test sensitivity and the large variations in herd
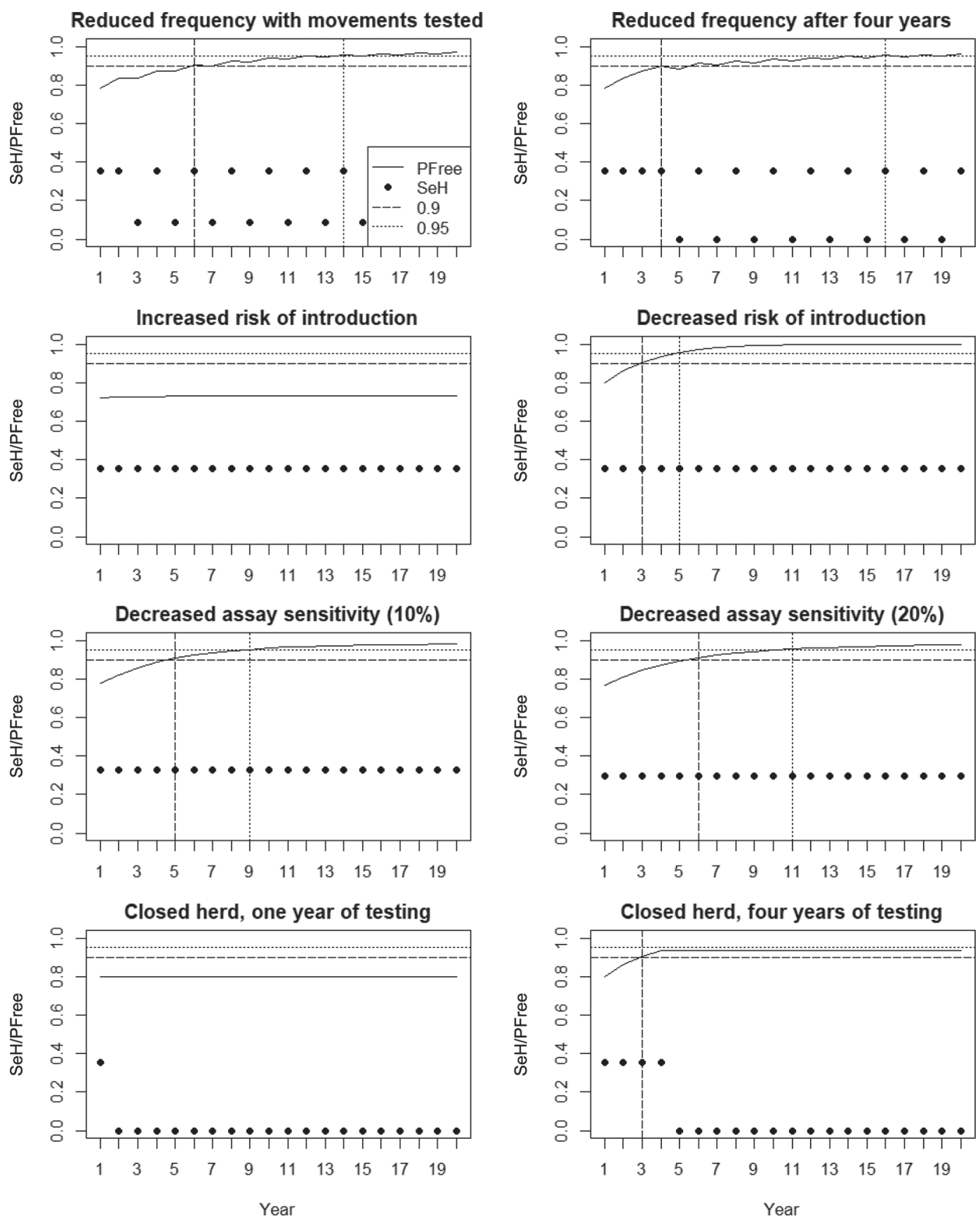

Figure 5 (Continued). Plots of the median confidence of freedom (Pfree, blue lines) and annual herd sensitivity (SeH, black dots) by year and scenario. The time until the median Pfree reaches 90\% (respectively, 95\%) is represented using a dashed red (respectively, black) line. 
sizes (Figure 1, upper left panel). The long tails in the estimates of the confidence of freedom at the end of the simulation (Figure 4) are likely due to the minority of herds that have large numbers of introductions (Figure 1 , lower left panel). This resulted in an increase in the probability of introduction each year, and therefore a decrease of the confidence of freedom for these herds over time. This was particularly evident in scenario 11, where the average prevalence of infection among source animals is much higher than in other scenarios. The sensitivity analysis also showed that the number of introductions in the herd was the most important factor affecting confidence of freedom over time. It is worth noting that the movement data used in our study were collected in 2015 and 2016, when the number of introductions in Irish dairy herds was at the highest level for more than a decade (DAFM, 2017).

Our results showed that the 2 current testing strategies (scenarios 1 and 4) provide similar levels of confidence that the herd is free from MAP infection at the end of the 20-yr period. However, as the herd-level sensitivity achieved with scenario 1 was higher, the confidence of freedom increases faster in the first years of testing than it does in scenario 4; this was mostly due to the effect of the increased frequency of milk testing in herds using milk tests. Importantly, we assumed that when 2 rounds of testing were conducted each year, the sensitivities of these tests were independent. We can reasonably think that this is not strictly the case (Gardner et al., 2000) and that, therefore, the true herd sensitivity (and resulting confidence of freedom) for scenario 1 is likely to be an overestimate of the true value. Although the degree of correlation and resulting bias in herd sensitivity and confidence of freedom using 2 tests per year is unknown, the true value is likely to lie somewhere between the estimates for scenarios 1 and 3. Scenario 1 also creates logistic issues around ensuring compliance and avoiding potential interference from bovine tuberculosis testing that are easier to avoid when testing only once a year.

Reducing the testing frequency to once a year in herds using milk and serum tests (scenario 3) removed the potential correlation bias but decreased the confidence of freedom to levels similar to those of scenario 4 (serum tests only), with overall testing costs only around half of those of scenario 4. As the confidence of

Table 3. Summary table of the confidence of freedom and testing costs after 5 and 20 yr, by scenario ${ }^{1}$

\begin{tabular}{|c|c|c|c|c|c|c|c|c|c|c|c|}
\hline \multirow{2}{*}{\multicolumn{2}{|c|}{ Scenario }} & \multicolumn{2}{|c|}{ PFree $^{2}$} & \multicolumn{2}{|c|}{$\begin{array}{c}\text { Cumulative } \\
\text { testing costs } \\
(€)\end{array}$} & \multicolumn{2}{|c|}{$\begin{array}{l}\text { Number of } \\
\text { tests over } \\
20 \mathrm{yr}\end{array}$} & \multicolumn{2}{|c|}{$\begin{array}{c}\text { Time to reach } \\
\text { specified } \\
\text { Pfree }(y r)\end{array}$} & \multicolumn{2}{|c|}{$\begin{array}{c}\text { Testing costs } \\
\text { to reach } \\
\text { specified } \\
\text { PFree }(€)\end{array}$} \\
\hline & & $5 \mathrm{yr}$ & $20 \mathrm{yr}$ & $5 \mathrm{yr}$ & $20 \mathrm{yr}$ & Milk & Serum & $90 \%$ & $95 \%$ & $90 \%$ & $95 \%$ \\
\hline 1 & $\begin{array}{l}\text { Milk or serum test twice a year } \\
\text { (current) }\end{array}$ & 0.975 & 0.994 & 2,511 & 10,036 & 2,640 & 160 & 2 & 4 & 1,004 & 2,009 \\
\hline 2 & Milk test only, once a year & 0.892 & 0.976 & 1,059 & 4,237 & 1,320 & 0 & 6 & 11 & 1,270 & 2,331 \\
\hline 3 & Milk or serum test once a year & 0.921 & 0.985 & 1,420 & 5,678 & 1,320 & 160 & 4 & 8 & 1,137 & 2,272 \\
\hline 4 & $\begin{array}{l}\text { Serum test once a year } \\
\text { (current) }\end{array}$ & 0.934 & 0.987 & 2,484 & 9,932 & 0 & 1,560 & 4 & 7 & 1,987 & 3,479 \\
\hline 5 & Older animals, milk or serum & 0.911 & 0.981 & 1,211 & 4,435 & 1,104 & 106 & 5 & 9 & 1,211 & 2,071 \\
\hline 6 & Older animals, serum only & 0.925 & 0.984 & 2,152 & 7,954 & 0 & 1,254 & 4 & 8 & 1,766 & 3,313 \\
\hline 7 & $\begin{array}{l}\text { Reduced frequency, milk or } \\
\text { serum }\end{array}$ & 0.852 & 0.959 & 852 & 3,125 & 726 & 88 & 8 & 18 & 1,420 & 2,840 \\
\hline 8 & Reduced frequency, serum only & 0.863 & 0.964 & 1,488 & 5,456 & 0 & 858 & 6 & 14 & 1,984 & 3,970 \\
\hline 9 & $\begin{array}{l}\text { Reduced frequency with } \\
\text { movements tested }\end{array}$ & 0.873 & 0.970 & 1,063 & 4,071 & 726 & 241 & 6 & 14 & 1,347 & 2,515 \\
\hline 10 & Reduced frequency after 4 yr & 0.886 & 0.962 & 1,136 & 3,408 & 792 & 96 & 4 & 16 & 1,136 & 2,556 \\
\hline 11 & Increased risk of introduction & 0.730 & 0.732 & 1,419 & 5,677 & 1,320 & 160 & $>20$ & $>20$ & $\mathrm{NA}^{3}$ & NA \\
\hline 12 & Decreased risk of introduction & 0.959 & $>0.999$ & 1,419 & 5,679 & 1,320 & 160 & 3 & 5 & 851 & 1,419 \\
\hline 13 & $\begin{array}{l}\text { Decreased assay sensitivity } \\
(10 \%)\end{array}$ & 0.908 & 0.982 & 1,419 & 5,676 & 1,320 & 160 & 5 & 9 & 1,419 & 2,553 \\
\hline 14 & $\begin{array}{l}\text { Decreased assay sensitivity } \\
(20 \%)\end{array}$ & 0.893 & 0.977 & 1,420 & 5,679 & 1,320 & 160 & 6 & 11 & 1,703 & 2,840 \\
\hline 15 & $\begin{array}{l}\text { Closed herd, } 1 \text { yr of testing } \\
\text { only }\end{array}$ & 0.800 & 0.800 & 284 & 284 & 66 & 8 & $>20$ & $>20$ & $\mathrm{NA}$ & NA \\
\hline 16 & $\begin{array}{l}\text { Closed herd, } 4 \text { yr of testing } \\
\text { only }\end{array}$ & 0.937 & 0.937 & 1,137 & 1,137 & 264 & 32 & 3 & $>20$ & 853 & NA \\
\hline
\end{tabular}

${ }^{1}$ The figures presented here correspond to the median of the corresponding outputs. They represent a summary estimate of the outputs across all possible values of the input variables, including herd size.

${ }^{2}$ Pfree $=$ confidence of freedom.

${ }^{3}$ Not applicable. 
freedom is mainly driven by the number of herd tests undertaken, it is worth noting that scenarios 1 and 3 require a similar number of herd tests to reach a given confidence of freedom; therefore, scenario 3 requires a longer time period because the testing frequency is inferior to that of scenario 1, other parameters being identical. A single annual whole-herd ELISA test (either milk or serum at owners' discretion) provides adequate confidence within a reasonable timeframe.

The most cost-effective alternative testing strategies were scenarios 5 and 6 . Testing only animals aged $3 \mathrm{yr}$ or older did not substantially decrease the overall confidence of freedom achieved at the end of the simulation period, but did lead to a reduction in total testing costs by around $20 \%$. The loss of herd-level sensitivity obtained when not testing the first-lactation animals was minimal (from 36 to $32 \%$ for the milk and serum scenarios and from 39 to $35 \%$ for the serum only scenarios). Reducing the testing to a single annual ELISA test in animals aged $3 \mathrm{yr}$ or older (either milk or serum as above) after 2 yr (Table 1) would therefore provide a cost-effective alternative to the current testing strategies.

The largest reduction in testing costs was obtained by reducing the frequency from every year to every second year. However, this resulted in a substantial decrease in the final confidence of freedom and delays in reaching target values due to the long interval between tests. Testing the entries and exits did not provide substantial benefits in terms of final confidence of freedom, as the number of entries and exits in a typical dairy herd tends to be relatively small; however, it reduced the time to reach $90 \%$ confidence of freedom by 2 yr. Likewise, comparisons between scenarios 3 and 4 (respectively, 5 and 6, 7 and 8) showed that the use of serum tests only, rather than milk or serum tests, provided only marginally improved outputs for substantially increased costs (for instance, total testing costs for scenario 4 were $85 \%$ higher than for scenario 3 ).

Scenarios 11, 12, 15, and 16 highlighted the importance of biosecurity practices. When the probability of introduction increased, the maximum confidence of freedom that can ever be reached decreased despite a reasonably good herd-level sensitivity. On the other hand, improved movement control practices, including the sourcing of animals from JD-free herds only or maintaining a closed herd, meant that the confidence of freedom would asymptotically reach 1 if the testing was maintained for a long enough duration. In such situations, it may be possible to decrease the testing intensity after the desired level of confidence in freedom is reached, as the confidence of freedom does not decrease over time when the probability of disease introduction is nil. However, a nil probability of introduction (or of prevalence exceeding the design prevalence of $5 \%$ ) is not truly achievable in many herds. For example, progression of low-prevalence infection (below the design prevalence of $5 \%$ ) or introduction of infection through contaminated manure or young animals exposed on grow-out farms could pose significant risks that are not accounted for in this model. Therefore, scenarios 12, 15 , and 16 should be interpreted with caution. Because of this ongoing risk, ongoing herd testing provides the only effective way of maintaining a high level of confidence; complete cessation of testing after only a minimal number of tests is not recommended. Not only is this important if individual herds maintain their level of assurance, it is also critical to provide confidence of the assurance status of tested herds for other producers wishing to purchase low-risk animals.

Finally, we considered that the VRAMP would modify the probability of introduction of infection into the herd through management of risks, such as introduction of live animals and manure. In addition to bio-exclusion, the VRAMP also has a focus on biocontainment. However, the type of model we used did not allow inclusion of within-herd infection dynamics; therefore, it was not possible to model the effect of VRAMP on MAP transmission within the herd.

Few studies evaluating the herd-level confidence of freedom provided by different JD testing strategies are available in the literature. The work presented here has many similarities to, and builds on, previous work undertaken in the Republic of Ireland (More et al., 2013); however, some fundamental differences exist, such that the 2 studies are not directly comparable. In the previous work, fixed herd sizes of 50 and 100 animals were modeled, whereas in our study actual herd sizes were used, ranging from 20 to over 1,000 animals. The current study assumes a design prevalence of $5 \%$ in most scenarios, compared with 2 values of $5 \%$ and 1 animal in the previous work. Further, numbers of animals introduced (and hence probability of disease introduction) is also based on actual data, compared with arbitrary values of 0 or 1 animal or $5 \%$ of the herd previously. Finally, both the prior confidence of freedom and the assumed prevalence in source herds for introductions were based on more recent data (McAloon et al., 2016a), compared with the work of More et al. (2013), which used data from 2005 (Good et al., 2009). Despite these differences, results for scenarios that are directly comparable are similar after allowing for the difference in prior confidence of freedom. Besides More et al. (2013), we are only aware of one other relevant paper (Sergeant et al., 2008) that investigated a similar question; however, those authors used a different meth- 
odology based on actual test results in Danish herds. In that study, the authors calculated the probability that the prevalence of MAP infection was below a selected design prevalence in herds with both negative and positive results in ELISA and fecal culture. Martin (2008) and Frössling et al. (2013) calculated the confidence of freedom from the disease in Western Australia and Sweden, respectively, based on past surveillance results. However, it is not possible to compare our results with the outcomes of those studies due to the major differences in study design. First, the level of both analyses was the population rather than the herd; additionally, we considered a specific disease surveillance activity in the current work (longitudinal serum and milk sampling), whereas the 2 studies cited above combined the results of several surveillance activities into the calculation of the confidence of freedom. Surveillance included clinical surveillance in both the dairy and beef sectors, cross-sectional surveys based on serum or fecal sampling or both, fallen stock investigations, and activities targeting imported cattle. Overall, analysis of past surveillance activities and modeling of hypothetical surveillance scenarios provide complementary insights that are both valuable for decision-makers involved in JD management, from the herd to the population level.

Last, we did not include environmental sampling in the present work, as it will be the subject of a separate piece of work within the same project. The use of environmental testing to identify the presence of MAP has been increasingly investigated in recent years (Lavers et al., 2013; Hahn et al., 2017) and could contribute to more cost-effective testing strategies when combined with traditional serum or milk sampling activities.

\section{CONCLUSIONS}

The modeling approach described in this paper provides a practical comparison of alternative JD testing strategies that could be implemented in Irish dairy herds. Some of the alternative scenarios achieved an acceptable level of confidence of freedom in a reasonable timeframe and at lesser cost than the current testing strategies. The results of this work will be used to provide recommendations for the next phases of the program.

\section{ACKNOWLEDGMENTS}

The authors thank members of the technical working group of the Irish Johne's Control Programme for helpful discussions during the preparation of this paper. The study was funded by the Irish Department of Agriculture, Food and the Marine (Dublin, Ireland).

\section{REFERENCES}

Acharya, K. R., N. K. Dhand, R. J. Whittington, and K. M. Plain. 2017. PCR inhibition of a quantitative PCR for detection of $M y$ cobacterium avium subspecies Paratuberculosis DNA in feces: Diagnostic implications and potential solutions. Front. Microbiol. 8:115. https://doi.org/10.3389/fmicb.2017.00115.

Alinovi, C. A., M. P. Ward, T. L. Lin, G. E. Moore, and C. C. Wu. 2009. Real-time PCR, compared to liquid and solid culture media and ELISA: For the detection of Mycobacterium avium ssp. paratuberculosis. Vet. Microbiol. 136:177-179.

Auguie, B. 2016. gridExtra: Miscellaneous functions for "grid" graphics. Accessed Nov. 13, 2017. https://cran.r-project.org/web/ packages/gridExtra/index.html.

Cameron, A. R. 2012. The consequences of risk-based surveillance: Developing output-based standards for surveillance to demonstrate freedom from disease. Prev. Vet. Med. 105:280-286. https://doi .org/10.1016/j.prevetmed.2012.01.009.

Cameron, A. R., and F. C. Baldock. 1998. Two-stage sampling in surveys to substantiate freedom from disease. Prev. Vet. Med. 34:19-30. https://doi.org/10.1016/S0167-5877(97)00073-1.

Chiodini, R. J., H. J. Van Kruiningen, W. R. Thayer, R. S. Merkal, and J. A. Coutu. 1984. Possible role of mycobacteria in inflammatory bowel disease. Dig. Dis. Sci. 29:1073-1079. https://doi.org/10 $.1007 / \mathrm{BF} 01317078$.

DAFM. 2017. Animal identification and movements-Bovine statistics annual reports. Department of Agriculture, Food and the Marine. Accessed Feb. 20, 2018. https://www.agriculture.gov.ie/ animalhealthwelfare/animalidentificationmovement/cattle/.

Frössling, J., H. Wahlström, E. C. C. Ågren, A. Cameron, A. Lindberg, and S. Sternberg Lewerin. 2013. Surveillance system sensitivities and probability of freedom from Mycobacterium avium ssp. paratuberculosis infection in Swedish cattle. Prev. Vet. Med. 108:47-62. https://doi.org/10.1016/j.prevetmed.2012.07.010.

Gardner, I. A., H. Stryhn, P. Lind, and M. T. Collins. 2000. Conditional dependence between tests affects the diagnosis and surveillance of animal diseases. Prev. Vet. Med. 45:107-122. https://doi .org/10.1016/S0167-5877(00)00119-7.

Geraghty, T., D. A. Graham, P. Mullowney, and S. J. More. 2014. A review of bovine Johne's disease control activities in 6 endemically infected countries. Prev. Vet. Med. 116:1-11. https://doi.org/10 .1016/j.prevetmed.2014.06.003.

Good, M., T. Clegg, H. Sheridan, D. Yearsely, T. O'Brien, J. Egan, and P. Mullowney. 2009. Prevalence and distribution of paratuberculosis (Johne's disease) in cattle herds in Ireland. Ir. Vet. J. 62:597-606. https://doi.org/10.1186/2046-0481-62-9-597.

Grant, I. R., E. I. Hitchings, A. McCartney, F. Ferguson, and M. T. Rowe. 2002. Effect of commercial-scale high-temperature, shorttime pasteurization on the viability of Mycobacterium paratuberculosis in naturally infected cows' milk. Appl. Environ. Microbiol. 68:602-607. https://doi.org/10.1128/AEM.68.2.602-607.2002.

Hahn, N., K. Failing, T. Eisenberg, K. Schlez, P. M. Zschock, K. Donat, E. Einax, and H. Kohler. 2017. Evaluation of different diagnostic methods for the detection of Mycobacterium avium ssp. paratuberculosis in boot swabs and liquid manure samples. BMC Vet. Res. 13:259. https://doi.org/10.1186/s12917-017-1173-6.

Hendrick, S. H., D. F. Kelton, K. E. Leslie, K. D. Lissemore, M. Archambault, and T. F. Duffield. 2005. Effect of paratuberculosis on culling, milk production, and milk quality in dairy herds. J. Am. Vet. Med. Assoc. 227:1302-1308. https://doi.org/10.2460/javma .2005 .227 .1302 .

Johnson-Ifearulundu, Y. J., J. B. Kaneene, D. J. Sprecher, J. C. Gardiner, and J. W. Lloyd. 2000. The effect of subclinical Mycobacterium paratuberculosis infection on days open in Michigan, USA, dairy cows. Prev. Vet. Med. 46:171-181. https://doi.org/10.1016/ S0167-5877(00)00145-8.

Jubb, T. F., E. S. G. Sergeant, A. P. L. Callinan, and J. W. Galvin. 2004. Estimate of the sensitivity of an ELISA used to detect Johne's disease in Victorian dairy cattle herds. Aust. Vet. J. 82:569-573. 
Kralik, P., R. Pribylova-Dziedzinska, A. Kralova, K. Kovarcik, and I. Slana. 2014. Evidence of passive faecal shedding of Mycobacterium avium ssp. paratuberculosis in a Limousin cattle herd. Vet. J. 201:91-94. https://doi.org/10.1016/j.tvjl.2014.02.011.

Lavers, C. J., S. L. McKenna, I. R. Dohoo, H. W. Barkema, and G. P. Keefe. 2013. Evaluation of environmental fecal culture for $M y$ cobacterium avium subspecies paratuberculosis detection in dairy herds and association with apparent within-herd prevalence. Can. Vet. J. 54:1053-1060.

Logar, K., R. Kopinc, P. Bandelj, J. Staric, A. Lapanje, and M. Ocepek. 2012. Evaluation of combined high-efficiency DNA extraction and real-time PCR for detection of Mycobacterium avium ssp. paratuberculosis in subclinically infected dairy cattle: comparison with faecal culture, milk real-time PCR and milk ELISA. BMC Vet. Res. 8:49. https://doi.org/10.1186/1746-6148-8-49.

Martin, P. A. J. 2008. Current value of historical and ongoing surveillance for disease freedom: surveillance for bovine Johne's disease in Western Australia. Prev. Vet. Med. 84:291-309. https://doi.org/10 .1016/j.prevetmed.2007.12.002.

Martin, P. A. J., A. R. Cameron, and M. Greiner. 2007. Demonstrating freedom from disease using multiple complex data sources 1: A new methodology based on scenario trees. Prev. Vet. Med. 79:7197. https://doi.org/10.1016/j.prevetmed.2006.09.008.

Martin, S. W., M. Shoukri, and M. A. Thorburn. 1992. Evaluating the health status of herds based on tests applied to individuals. Prev. Vet. Med. 14:33-43. https://doi.org/10.1016/0167-5877(92)90082 $-\mathrm{Q}$.

McAloon, C. G., M. L. Doherty, P. Whyte, L. O'Grady, S. J. More, L. L. M. Messam, M. Good, P. Mullowney, S. Strain, and M. J. Green. 2016a. Bayesian estimation of prevalence of paratuberculosis in dairy herds enrolled in a voluntary Johne's Disease control program in Ireland. Prev. Vet. Med. 128:95-100. https://doi.org/ 10.1016/j.prevetmed.2016.04.014.

McAloon, C. G., P. Whyte, S. J. More, M. J. Green, L. O'Grady, A. Garcia, and M. L. Doherty. 2016b. The effect of paratuberculosis on milk yield - A systematic review and meta-analysis. J. Dairy Sci. 99:1449-1460. https://doi.org/10.3168/jds.2015-10156.

Meyer, A., K. Bond, S. Van Winden, M. Green, and J. Guitian. 2018. A probabilistic approach to the interpretation of milk antibody results for diagnosis of Johne's disease in dairy cattle. Prev. Vet. Med. 150:30-37. https://doi.org/10.1016/j.prevetmed.2017.11.016.

More, S. J., M. L. Doherty, L. Downey, K. McKenzie, C. Devitt, and J. O'Flaherty. 2011. Animal Health Ireland: Providing national leadership and coordination of non-regulatory animal health issues in Ireland. Rev. Sci. Tech. 30:715-723.

More, S. J., K. McKenzie, J. O'Flaherty, M. L. Doherty, A. R. Cromie, and M. J. Magan. 2010. Setting priorities for non-regulatory animal health in Ireland: Results from an expert Policy Delphi study and a farmer priority identification survey. Prev. Vet. Med. 95:198-207. https://doi.org/10.1016/j.prevetmed.2010.04.011.

More, S. J., E. S. G. Sergeant, S. Strain, W. Cashman, K. Kenny, and D. Graham. 2013. The effect of alternative testing strategies and bio-exclusion practices on Johne's disease risk in test-negative herds. J. Dairy Sci. 96:1581-1590. https://doi.org/10.3168/jds .2012-5918

Nielsen, S. S., C. Enevoldsen, and Y. T. Gröhn. 2002a. The Mycobacterium avium ssp. paratuberculosis ELISA response by parity and stage of lactation. Prev. Vet. Med. 54:1-10. https://doi.org/10 .1016/S0167-5877(02)00008-9.

Nielsen, S. S., and N. Toft. 2008. Ante mortem diagnosis of paratuberculosis: A review of accuracies of ELISA, interferon- $\gamma$ assay and faecal culture techniques. Vet. Microbiol. 129:217-235. https://doi .org/10.1016/j.vetmic.2007.12.011.

Nielsen, S. S., C. Gronbaek, J. F. Agger, and H. Houe. 2002b. Maximum-likelihood estimation of sensitivity and specificity of ELISAs and faecal culture for diagnosis of paratuberculosis. Prev. Vet. Med. 53:191-204. https://doi.org/10.1016/S0167-5877(01)00280 $-\mathrm{X}$.

Nielsen, S. S., N. Toft, and H. Okura. 2013. Dynamics of specific anti-Mycobacterium avium ssp. paratuberculosis antibody response through age. PLoS One 8:e63009. https://doi.org/10.1371/journal .pone.0063009.

Plain, K. M., I. B. Marsh, A. M. Waldron, F. Galea, A.-M. Whittington, V. F. Saunders, D. J. Begg, K. de Silva, A. C. Purdie, and R. J. Whittington. 2014. High-throughput direct fecal PCR assay for detection of Mycobacterium avium ssp. paratuberculosis in sheep and cattle. J. Clin. Microbiol. 52:745-757. https://doi.org/ 10.1128/JCM.03233-13.

Pozzato, N., K. Capello, A. Comin, N. Toft, S. S. Nielsen, G. Vicenzoni, and N. Arrigoni. 2011. Prevalence of paratuberculosis infection in dairy cattle in Northern Italy. Prev. Vet. Med. 102:83-86. https://doi.org/10.1016/j.prevetmed.2011.07.001.

R Core Team. 2017. R: A Language and Environment for Statistical Computing. R Foundation for Statistical Computing, Vienna, Austria.

Richardson, E., and S. J. More. 2009. Direct and indirect effects of Johne's disease on farm and animal productivity in an Irish dairy herd. Ir. Vet. J. 62:526. https://doi.org/10.1186/2046-0481-62-8 -526 .

Rogan, W. J., and B. Gladen. 1978. Estimating prevalence from the results of a screening test. Am. J. Epidemiol. 107:71-76. https:// doi.org/10.1093/oxfordjournals.aje.a112510.

Sergeant, E. S. G., S. S. Nielsen, and N. Toft. 2008. Evaluation of teststrategies for estimating probability of low prevalence of paratuberculosis in Danish dairy herds. Prev. Vet. Med. 85:92-106. https: //doi.org/10.1016/j.prevetmed.2008.01.005.

Sweeney, R. W. 2011. Pathogenesis of paratuberculosis. Vet. Clin. North Am. Food Anim. Pract. 27:537-546. https://doi.org/10 .1016/j.cvfa.2011.07.001.

van Weering, H., G. van Schaik, A. van der Meulen, M. Waal, P. Franken, and K. van Maanen., K. 2007. Diagnostic performance of the Pourquier ELISA for detection of antibodies against $\mathrm{Myco-}$ bacterium avium subspecies paratuberculosis in individual milk and bulk milk samples of dairy herds. Vet. Microbiol. 125:49-58. https: //doi.org/10.1016/j.vetmic.2007.05.010.

Vose, D. 2000. Risk Analysis: A Quantitative Guide. 2nd ed. Wiley, Chichester, UK

Waddell, L., A. Rajic, K. Stark, and S. A. McEwen. 2016. Mycobacterium avium ssp. paratuberculosis detection in animals, food, water and other sources or vehicles of human exposure: A scoping review of the existing evidence. Prev. Vet. Med. 132:32-48. https://doi .org/10.1016/j.prevetmed.2016.08.003.

Waddell, L. A., A. Rajic, K. D. C. Stark, and S. A. McEwen. 2015. The zoonotic potential of Mycobacterium avium ssp. paratuberculosis: A systematic review and meta-analyses of the evidence. Epidemiol. Infect. 143:3135-3157. https://doi.org/10.1017/ S095026881500076X.

Wickham, H. 2009. Ggplot2: Elegant Graphics for Data Analysis. Springer-Verlag, New York, NY. 


\section{APPENDIX}

Figure A1 shows the results of the sensitivity analysis on the level of design prevalence used in scenarios 1,3 , and 5. Lower design prevalence levels were associated with longer durations to reach specified levels of confidence of freedom, as infected animals were less likely to be detected when the disease prevalence decreased.
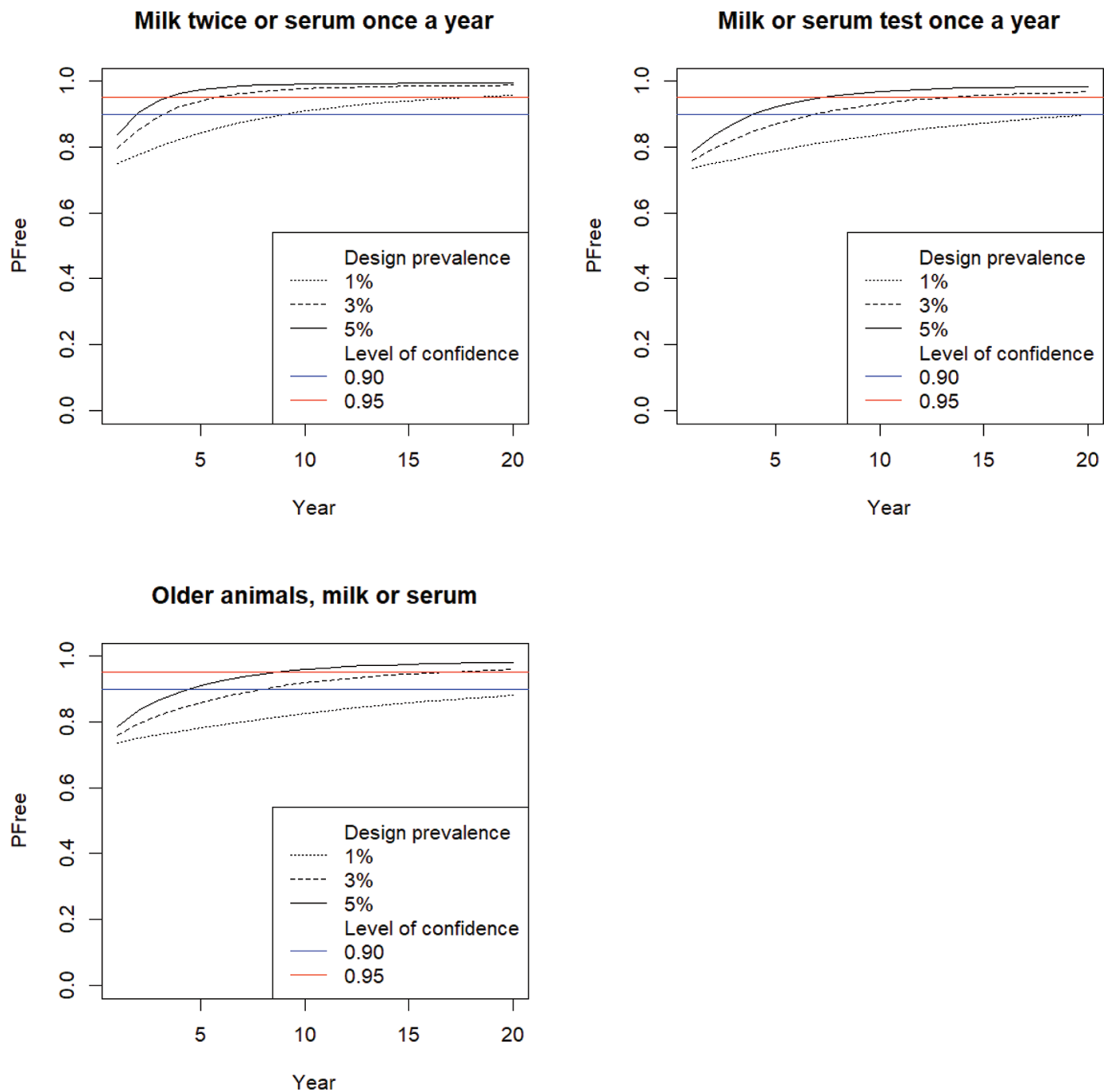

Figure A1. Plots of the median confidence of freedom (Pfree, black lines) for scenarios 1, 3, and 5 and levels of design prevalence (1, 3 and $5 \%$, respectively). 